\title{
EFEITOS DA APLICACÃO DE FERTILIZANTES COMERCIAIS, VIA FOLIAR, EM GLOXÍNEA \\ (Sinningia speciosa, Hiern) *
}

\author{
José Francisco N. Bittencourt ** \\ Pedro Dantas Fernandes \\ JaIRo Ribeiro DE Mattos ****
}

RESUMO

O presente trabalbo teve por ohjetivo estudar a resposta da Gloxínea (Sinningiut speciosu, Hiern) à aplicação de fertilizantes comerciais, via foliar. Foram testados Yogen n. ${ }^{\circ}$ 2, Alimento para Plantas e Wuxal. Yogen foi o de melhor efeito, aumentandos o período de florescimento em mais de dez dias e duplicantis o número de flores produzidas, quando aplicado em intervalo de 10 e de 20 dias.

\section{INTRODUÇÃO}

As gloxíneas, do gênero Sinningia são plantas herbáceas, cultivadas em vasos, pela grande beleza de suas flores vistosas e grandes. A maioria das espécies existentes são originárias das matas virgens brasileiras, normalmente das zonas tropicais, de muito calor e umidade (TEIXEIRA, 1954, 1971).

Apesar de ter origem no Brasil, todos os trabalhos de melhoramento foram realizados a partir de 1825 , em países europeus conquistando o interesse dos floricultores de todo o mundo, sob o nome de gloxínea, e como planta floral de cultivo em vasos, já se coloca ao lado de outras flores ornamentais há séculos cultivadas (TEIXEIRA, 1971).

* Entregue para publicação em 29-3-77.

* Escola de Agronomia da U.F.S.C., Florianópolis, S.C.

*** Faculdade de Ciências Agrárias e Veterinárias, Jaboticabal, SP.

**** E.S.A. "Luiz de Queiroz" - Piracicaba, SP. 
LAURIE, KIPLINGER \& NELSON (1958) consideram que para o plantio de gloxínea, uma adubação completa é satisfatória. TEIXEIRA (1971) cita que no Setor de Floricultura da Universidade da Califórnia, é usada uma mistura de areia fina, turfa, dolomita, calcário, nitrato de potássio, superfosfato e sangue dessecado. ROGASHI $(1967 / 1968)$ não recomenda adubação em cobertura para as gloxíneas.

Em nossas condições são inexistentes dados experimentais, sendo todas as orientações de cultivo baseadas em tentativas práticas. Os floricultores fazem adubação foliar com vários produtos encontrados no mercado, mas sem terem dados técnicos como orientação.

Os objetivos do presente trabalho foram estudar os efeitos de aplicação de fertilizantes comerciais, via foliar, sobre o período de florescimento, número de flores e produção de bulbos de gloxínea.

\section{MATERIAIS E METODOS}

Sementes $\mathrm{F}_{1}$ de híbridos de Sinningia speciosa, Hiern, foram distribuídas a lanço em uma caixa contendo terra preparada, a 02/04/1974. A germinação ocorreu após 8 dias da semeadura.

Obtidas as mudas, quando apresentavam de 2 a 4 folhas, foi feita repicagem para caixas maiores, ficando espaçadas de $10 \times 15 \mathrm{~cm}$. Essas caixas foram mantidas à meia sombra e temperatura entre 20 a $25^{\circ} \mathrm{C}$. A irrigação usada foi por capilaridade.

Para o transplante, realizado em $20 / 07 / 74$, foram utilizados vasos de cerâmica de $20 \mathrm{~cm}$ de diâmetro. O substrato foi o mesmo empregado na semeadura, constando de $1 / 4$ de esterco curtido de curral, $1 / 4$ de areia fina e $2 / 4$ de terriço de mata, convenientemente misturados e esterilizados. Análises químicas dessa mistura revelaram os valores contidos no QUADRO 1.

Após o transplante, os ensaios foram conduzidos em ripado, com cobertura de plástico transparente. Para os estudos de adubação foliar, foram testados os seguintes produtos: Yogen n. ${ }^{\circ} 2$ (Fertilizantes Mitsui S.A.), Alimento para Plantas (Rhodia) e Wuxal (Philips Duphar). A constituição química desses produtos está contida no QUADRO 2. Foram os seguintes, os tratamentos:

1. Testemunha;

2. Yogen, $2 \mathrm{~g} /$ litro, de 10 em 10 dias;

3. Yogen, $2 \mathrm{~g}$ /litro, de 20 em 20 dias;

4. Yogen, $2 \mathrm{~g} /$ litro, de 30 em 30 dias;

5. Alimento para plantas, $0,5 \mathrm{ml} /$ litro, a cada 10 dias;

6. Alimento para plantas, $0,5 \mathrm{ml} /$ litro, a cada 20 dias; 
7. Alimento para plantas, $0,5 \mathrm{ml} /$ litro, a cada 30 dias;

8. Wuxal, $1,0 \mathrm{ml} /$ litro, a cada 10 dias;

9. Wuxal, $1,0 \mathrm{ml} /$ litro, a cada 20 dias;

10. Wuxal, $1,0 \mathrm{ml} /$ litro, a cada 30 dias.

Essas doses utilizadas basearam-se em recomendações das firmas produtoras. As aplicações foliares iniciaram-se uma semana após o transplante das mudas para os vasos, e eram aplicados $200 \mathrm{ml} /$ planta da solução, molhando totalmente a planta.

QUADRO 1 - Dados de análise química da mistura usada como substrato nos ensaios.

\begin{tabular}{lc}
\hline $\mathrm{pH}$ & 5,80 \\
Carbono $(\%)$ & 1,58 \\
$\mathrm{PO}_{4}^{--}$trocável, e.mg/100 g solo & 0,30 \\
$\mathrm{Ca}^{++}$trocável, e.mg/100 g solo & 2,20 \\
$\mathrm{Ca}^{++}$trocável, e.mg/100 g solo & 2,20 \\
$\mathrm{Mg}^{++}$trocável, e.mg/100 g solo & 2,20 \\
$\mathrm{Al}++$ trocável, e.mg/100 g solo & 0,00 \\
\hline
\end{tabular}

QUADRO 2 - Constituição química dos produtos comerciais testados, através de adubação foliar.

\begin{tabular}{|c|c|c|c|c|c|c|c|c|c|c|c|c|}
\hline \multirow{2}{*}{ Produto } & \multicolumn{12}{|c|}{ Nutrientes $(\%)$} \\
\hline & $\mathrm{N}$ & $\mathrm{P}_{2} \mathrm{O}_{5}$ & $\mathrm{~K}_{2} \mathrm{O}$ & $\mathrm{MgO}$ & $\mathrm{S}$ & $\mathrm{B}_{2} \mathrm{O}_{3}$ & $\mathrm{Fe}$ & $\mathrm{C} \mathfrak{}$ & $\mathrm{MnO}$ & $\mathrm{HO}$ & $Z_{n}$ & $\mathrm{Na}$ \\
\hline Yogen $1 .^{\circ} 2$ & 30,0 & 10,0 & 10,0 & 0,10 & - & 0,05 & - & - & 0,10 & - & 0,05 & - \\
\hline $\begin{array}{l}\text { Alimento } \\
\text { para } \\
\text { Plantas }\end{array}$ & 11,0 & 3,0 & 4,0 & 0,10 & 0.20 & 0,01 & 0,01 & 0,01 & 0,01 & 0,001 & 0,1 & 0,01 \\
\hline Wuxal & 9,0 & 9,0 & 7,0 & - & - & 0,01 & 0,008 & 0,0185 & 0,016 & 0,00095 & 0,006 & 0,018 \\
\hline
\end{tabular}

O ensaio foi em blocos casualizados, com três repetições, sendo cada parcela representada por cinco vasos, uma planta por vaso.

Foram coletados dados referentes ao período de florescimento, número de bulbos viáveis por parcela e número total de bulbos produzidos por parcela. Para as análises estatísticas seguiram-se orientações contidas em PIMENTEL GOMES (1974). 


\section{RESULTADOS E DISCUSSÃO}

Os dados de período de florescimento, em dias, estão contidos na FIGURA 1. Mesmo não havendo significância dos tratamentos, observa-se que foi aumentado o número de dias de florescimento das plantas, com os adubos aplicados via foliar. Nos tratamentos 2, 3, 4, (aplicação de Yogen), o florescimento se prolongou por mais de dez dias. Considerando o comércio desta flor, como planta de vaso, apreende-se a importância de tais tratamentos.

A FIGURA 2 contém os dados médios de número de flores por planta, produzidas durante o ciclo. Houve diferenças significativas entre os tratamentos, resultando na maior produção de flores, principalmente com aplicação de Yogen n. ${ }^{\circ}$ 2, aplicado com intervalo de 10 e 20 dias (tratamentos 2 e 3 ). Em relação à testemunha, o número de flores produzidas foi superior em mais de cem por cento.

Pelo QUADRO 2, exposto anteriormente, verifica-se que, há diferenças entre os produtos, em relação à composição química, que explica estas diferenças encontradas no presente trabalho. Além de sua composição química, as doses recomendadas pelas respectivas firmas produtoras são diferentes. Há necessidade de serem testadas doses equivalentes dos fertilizantes, com base na constituição química, mesmo que não sejam obedecidas as recomendações dos fabricantes.

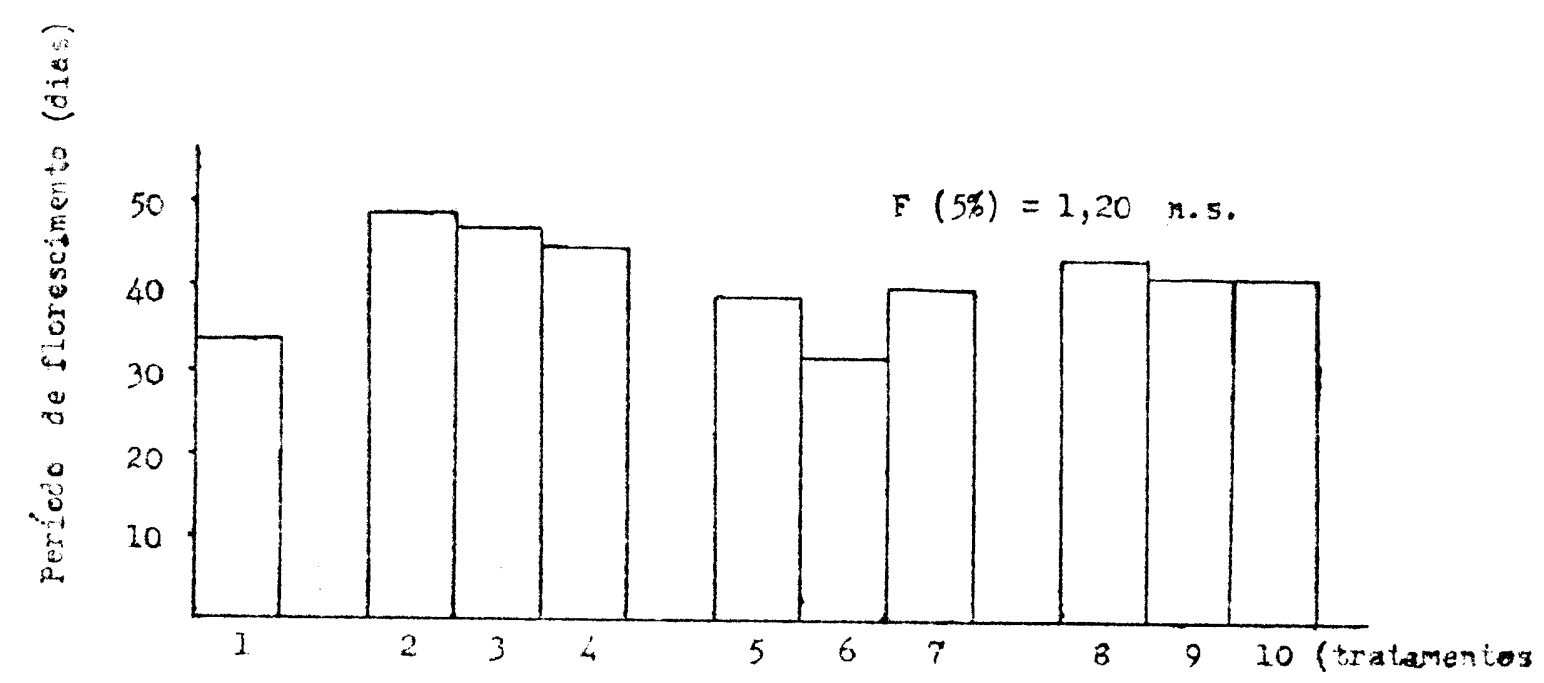

Figura 1 - Dados médios de duração do período de florescimento, em dias, segundo os tratamentos. 


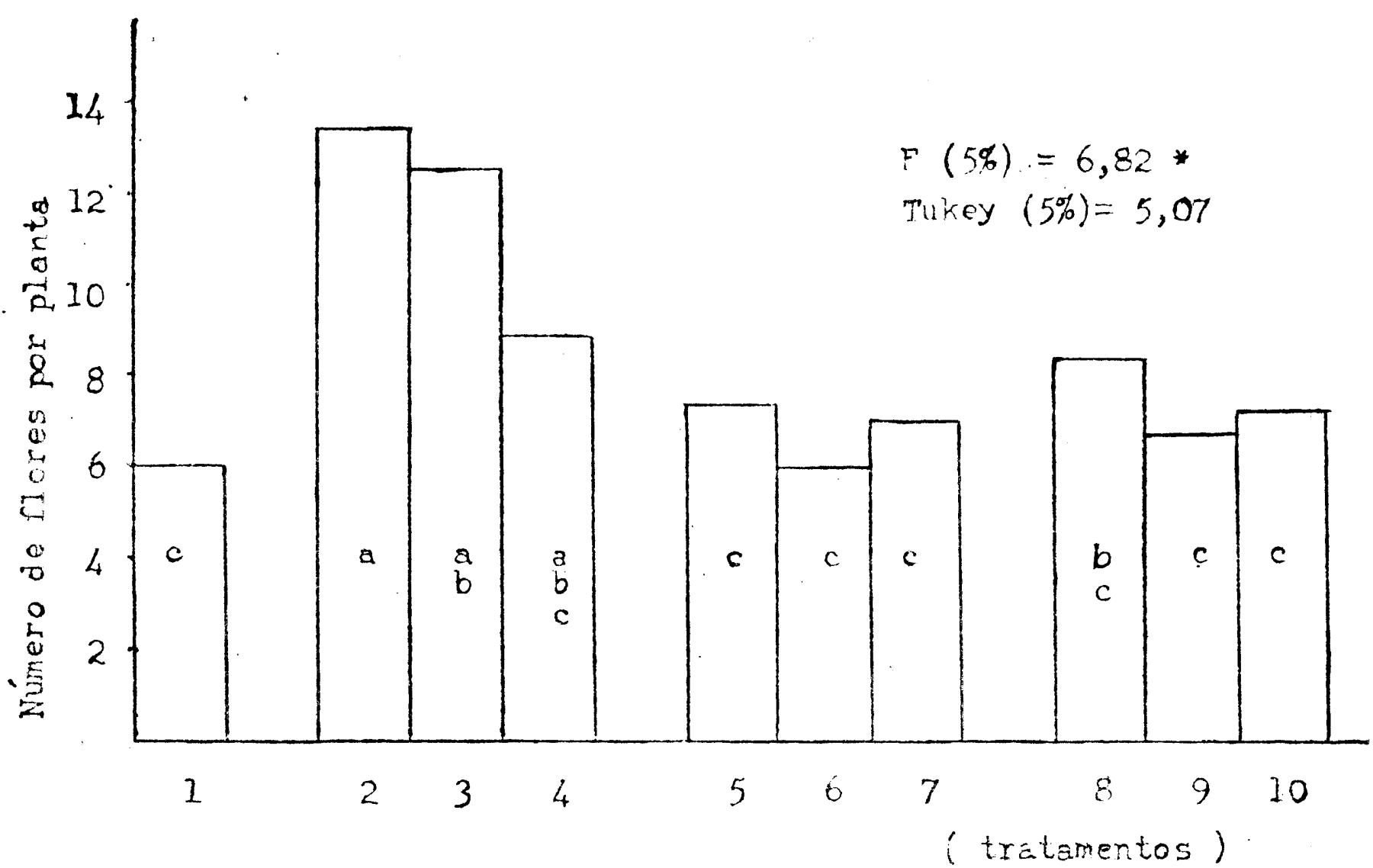

Figura 2 - Dados médios de número de flores por planta, produzidas durante o ciclo, segundo os tratamentos. (Colunas contendo mesma letra não diferem entre si estatisticamente).

Os dados de número total de bulbos produzidos e de número de bulbos viáveis, por parcela, estão expostos na FIGURA 3 . O critério de separação de bulbos viáveis, foi baseado na sua capacidade de bro-

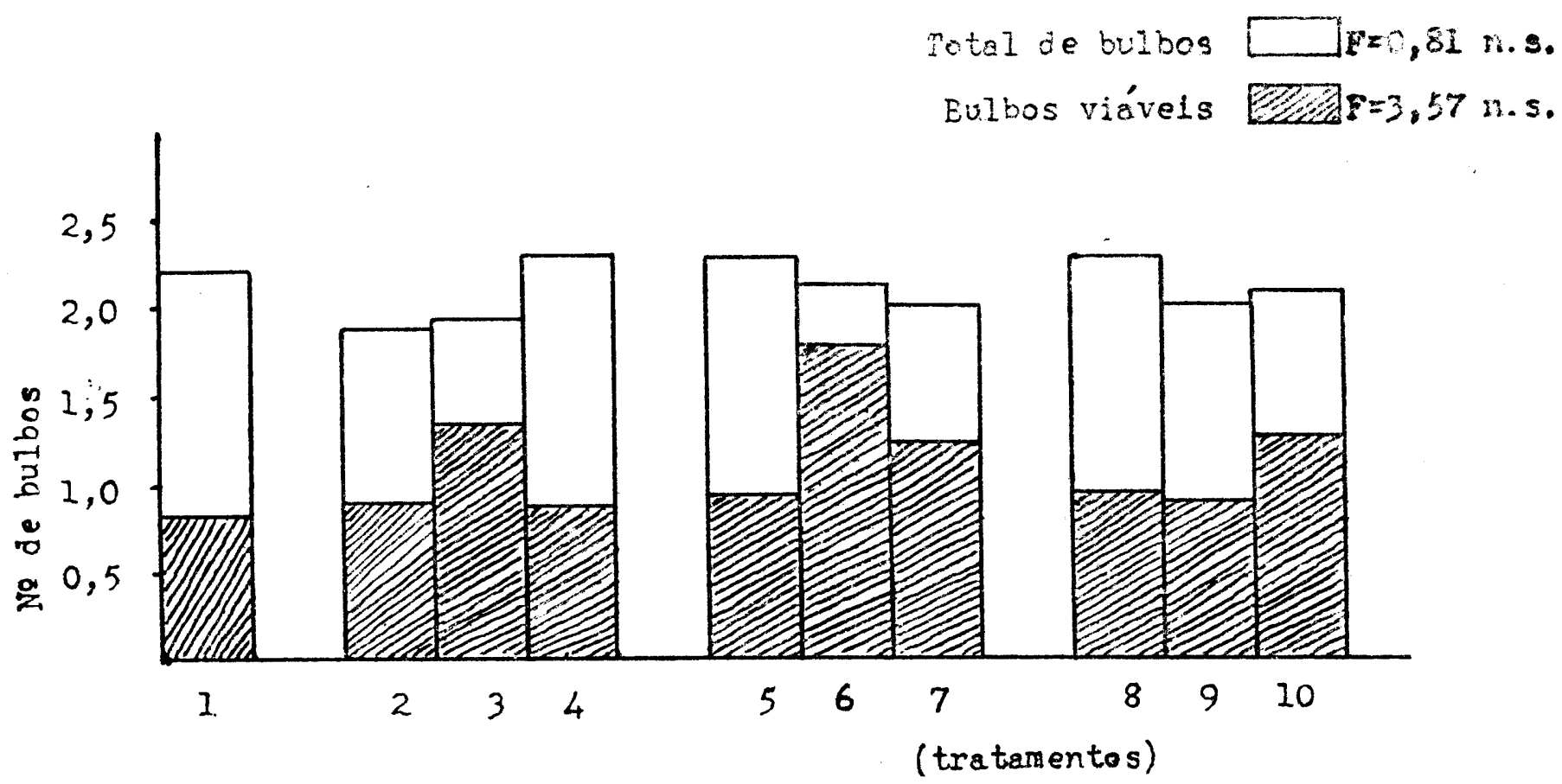

Figura 3 - Número total de bulbos produzidos e número de bulbos viáveis, por parcela, de acordo com os tratamentos. 
tação no ciclo seguinte. Observa-se que os fertilizantes testados não tiveram efeito significativo, embora alguns tratamentos tenham propiciado um maior número de bulbos viáveis.

\section{CONCLUSÕES}

Para as condições do presente trabalho, conclui-se que:

- Com o uso de Yogen n. ${ }^{\circ}$ 2, o período de florescimento foi aumentado em mais de dez dias;

- Yogen n. ${ }^{\circ}$ 2, aplicado em intervalos de 10 e 20 dias proporcionou aumento superior a $100 \%$ no número de flores produzidas;

- Não houve efeitos sobre a produção de bulbos.

SUMMARY

\section{EFFECTS OF COMERCIAL FERTILIZERS APPLICATION ON SINNINGIA SPECIOSA, HIERN.}

The present work was carried out in order to study the application of three comercial fertilizers in gloxinea (Sinningia speciosa, Hiern). Yogen $n .^{\circ} 2$ increased the flowering period through more than ten days and improved the flower production in about truice more flowers than the control, when it was applied each 10 and each 20 days.

\section{LITERATURA CITADA}

LAURIE, A.; KIPLINGER, D.C. ; NELSON, K.S. G Gloxinia. In: Commercial flower forcing. $6{ }^{3}$ ed. New York, McGraw-Hill Bock, 1958. p. 383-384.

PIMENTEL GOMES, F.. Curso de estatística experimental. 3. ed. Priacicaba, ESALQ. 166. $404 \mathrm{p}$.

TEIXEIRA, E.F.. A gloxínia: uma flor brasileira. Flores do Brasil, (1) : 47-50, 1954.

TEIXEIRA, E.F.. Flores brasileiras. São Paulo, /s.c.p./, 1971. p. 27-33.

TOGASHI, M.. Floricultura, novas e mais belas variedades. Guia Rural Coopercotia, $67 / 68: 112-114,1968$. 